\title{
Comparison of cisplatin-paclitaxel combination versus cisplatin-etoposide in patients with small-cell lung cancer: A Phase III study
}

\author{
JOHN DIMITROULIS ${ }^{1}$, ANGELIKI RAPTI ${ }^{1}$, GEORGE P. STATHOPOULOS ${ }^{2}$, SOTIRIS RIGATOS ${ }^{2}$, \\ JOHN STATHOPOULOS ${ }^{2}$, JOHN KOUTANTOS ${ }^{2}$, ATHANASIOS ATHANASIADIS ${ }^{3}$, \\ KYRIAKI TSIKRITSAKI $^{1}$, DIMITRIS KARAINDROS ${ }^{4}$, KOSTAS KATIS $^{4}$, DIMOSTHENIS ANTONIOU ${ }^{1}$, \\ MICHALIS TOUMBIS $^{1}$ and PANTELIS GIAMBOUDAKIS ${ }^{1}$ \\ ${ }^{1}$ Hospital of Thoracic Diseases; ${ }^{2}$ First Department of Oncology, Errikos Dunant Hospital, Athens; \\ ${ }^{3}$ General Hospital of Larissa; ${ }^{4}$ Thriacion Hospital, Athens; Solca Group Athens, Greece
}

Received May 28, 2008; Accepted July 21, 2008

DOI: 10.3892/or_00000086

\begin{abstract}
Cisplatin-paclitaxel and cisplatin-etoposide combination therapies were compared in limited and extensive disease in patients with small-cell lung cancer. The primary objectives were to determine median and overall survival, time to tumor progression and tolerance and the secondary objective, the response rate. From January 2003 till July 2007, 108 patients were enrolled in the study. All patients had histologically- or cytologically-confirmed smallcell lung cancer. All patients were chemotherapy and radiotherapy naive. The patients were designated to receive six cycles: in the investigational Arm A, cisplatin, $80 \mathrm{mg} / \mathrm{m}^{2}$ and paclitaxel $175 \mathrm{mg} / \mathrm{m}^{2}$ were infused on day 1 (1 cycle) and repeated every 3 weeks. In the control Arm B, cisplatin, 80 $\mathrm{mg} / \mathrm{m}^{2}$ was administered on day 1 and etoposide, $120 \mathrm{mg} / \mathrm{m}^{2}$ per day was given on days 1-3 (1 cycle), every 3 weeks. In Arm A, 6 (11.3\%) patients achieved a complete response and $32(58.1 \%)$, a partial response; in Arm B, 7 (12.7\%) patients achieved a complete response and $32(58.2 \%)$ a partial response. The median survival time in Arm A patients was 12 months and in Arm B, 13 months, $\mathrm{p}=0.354$. The time to tumor progression (TTP) was 8 and 6 months for Arms A and $\mathrm{B}$, respectively $(\mathrm{p}=0.060)$. Toxicity, although common in both Arms, was acceptable. Neutropenia, anemia and diarrhea were higher in the control Arm. The cisplatinpaclitaxel combination is not superior to cisplatin-etoposide with respect to survival, TTP, toxicity and response rate. The former combination could be applied as an alternative chemotherapy regimen for patients with limited or advanced small-cell lung cancer.
\end{abstract}

Correspondence to: Dr G.P. Stathopoulos, Semitelou 2A, 11528 Athens, Greece

E-mail: dr-gps@ath.forthnet.gr

Key words: cisplatin, paclitaxel, small-cell lung cancer

\section{Introduction}

Small-cell lung cancer (SCLC) is a common malignancy which is detected in nearly $20 \%$ of patients with lung cancer (1). It is tumor sensitive to chemotherapy and radiation therapy as the great majority of treated patients achieve complete and partial responses $(2,3)$. However, it is unfortunate that in nearly $85-90 \%$ of these patients, even with limited disease, the disease will recur. A great number of cytotoxic agents as well as a wide variety of regimen combinations have been used in treating this disease. Cisplatin (CDDP) and etoposide were initially developed as salvage treatment in pretreated patients (4). In parallel, alkylating agents, anthracyclines, CDDP, vinca alkaloids and recently taxanes and camptothecins have been tested (5-7). Past trials ended up with the combination of cyclophosphamide, doxorubicin and vincristine (CAV) which, in extensive disease, demonstrated overall response rates of 55-65\%, including complete response rates of $10-15 \%$. Five-year survival was observed in a small number of patients (8,9; Livingston RB, Proc ASCO 2: abs. 187, 1983). CAV was eventually compared with the etoposide and CDDP combination. These two schedules were considered to be the most effective ones. One randomized trial used cyclophosphamide, vincristine and prednisone (CVP) in one group of patients and in the second, etoposide and cisplatin (EP) were given alternatively with CVP. No significant difference was detected with respect to response rate and survival between the two treatments (10). Etoposide became an eligible agent for SCLC as it had been tested as monotherapy, administered for several consecutive days and showed an $81-87 \%$ response rate and a median survival of 7.1-9.4 months (2).

Numerous other agents and combinations were tested over the years and the EP combination was shown to be one of the best. A few years ago, another randomized trial was performed comparing etoposide-cisplatin with cyclophosphamide, epirubicin and vincristine (CEV) in small-cell lung cancer. It was observed that in limited disease, EP was more effective as the median and overall survival was statistically longer than with CEV. In extensive disease no difference was 
observed between the two regimens with respect to survival (11). Toxicity was quite high particularly with the EP group. Similar studies have been performed with approximately the same results and these will be discussed $(12,13)$.

The combination of etoposide and cisplatin has been established as a first-line treatment for small-cell lung cancer in both extensive and limited disease (in the latter, the treatment was combined with radiation therapy).

In the present trial we attempted to compare the EP schedule with a regimen combining paclitaxel (PCT) with CDDP. PCT has had prior testing as a third agent combined with EP and no difference was observed in either survival or the response rate and the 3-drug schedule was very toxic (14). In our trial, we substituted etoposide with PCT. Our primary objectives were to determine median and overall survival and toxicity, and secondary objective, response rate and time to tumor progression (TTP).

\section{Patients and methods}

Eligibility criteria included: patients with limited and extensive small-cell lung cancer, histologically- or cytologicallyconfirmed; a performance status (PS) of $\leq 2$ (ECOG scale) and a life expectancy of at least 12 weeks. Patients were required to have adequate bone marrow function (absolute neutrophil count $\geq 1.5 \times 10^{9} / 1$, platelet count $\geq 100 \times 10^{9} / 1$ and hemoglobin $\geq 100 \mathrm{gr} / \mathrm{l}$ ), adequate liver function (total bilirubin $\leq 1.5$ times the upper normal limit, AST and/or ALT $\leq 3$ times the upper normal limit) and a creatine clearance rate of $\geq 60 \mathrm{ml} / \mathrm{min}$. Patients with asymptomatic brain metastases were eligible. Patients with cardiac arrhythmias, heart failure, AV block or acute myocardial infarction within 4 months before study entry, as well as those with concurrent or previous malignancies (except adequately treated squamous-cell carcinoma of the skin) were excluded. The lower age limit for enrollment was 18 years. All patients gave their written informed consent and the protocol was approved by the Hospitals and local Ethics regulatory bodies.

Study design and sample size. This study was designed as a multicenter, randomized, Phase III trial, with four participating hospitals. The study was powered at $80 \%$ to detect a difference in response rate and survival between the investigational Arm and the control Arm. The sample size was initially planned to include 60 patients, 30 in each Arm with an increase in the number of patients if a statistical difference of $5 \%$ between the two Arms, with regard to median survival and response rate, was not reached. The randomization was performed centrally and patients were stratified by three prognostic variables: disease stage (limited versus extensive disease), PS of 0-2 and investigational site.

Treatment plan. Arm A patients (investigational Arm) were designated to receive six cycles of CDDP-PCT. The doses were PCT, $175 \mathrm{mg} / \mathrm{m}^{2}$ for a 3 -h infusion and CDDP, $80 \mathrm{mg} / \mathrm{m}^{2}$ for a 2 -h infusion and 21 hydration (1 1 normal saline and 11 electrolyte). Treatment was repeated every 21 days. Arm B, the control Arm, was designated to receive CDDP $80 \mathrm{mg} / \mathrm{m}^{2}$ as in the Arm A, on day 1 and etoposide (VP-16) $120 \mathrm{mg} / \mathrm{m}^{2}$ infusion for $20 \mathrm{~min}$ per day on days $1-3$, both repeated every 21 days. Treatment was performed in a one-day clinic. Patients that responded to the treatment continued up to the end of six cycles. Hemopoietic growth factor was not applied prophylactically, but only in cases of grade 3 and 4 neutropenia.

Baseline and treatment assessment and evaluation. Before study entry all patients underwent the following evaluations: medical history, physical examination, tumor measurement or evaluation, ECOG performance status, ECG, full blood count, liver and renal function test, and urinalysis. Staging was determined by chest and abdominal computed tomography, bone scan and occasionally magnetic resonance imaging. Blood count, blood urea and serum creatinine were measured before each treatment administration and 7 days after each course. Radiologic tests were conducted after the then current course of treatment if the clinical signs were indicative of disease progression.

For the assessment of response, we used imaging-based evaluation. A complete response (CR) was defined as the disappearance of all measurable disease confirmed at 4 weeks at the earliest; partial response (PR), a $30 \%$ decrease in tumor burden, also confirmed at 4 weeks at the earliest. In stable disease (SD) neither PR nor progressive disease (PD) criteria were met; PD, a $20 \%$ increase in tumor burden and no CR, PR or SD before increased disease. Response data were based on the Response Evaluation Criteria in Solid Tumors (RECIST) (15). A two-step deterioration in performance status, a $>10 \%$ loss in pretreatment weight or increasing symptoms did not, by themselves, constitute progression of the disease; however, the appearance of these complaints was followed by a new evaluation of the extent of the disease. All responses had to be maintained for at least 4 weeks and to be confirmed by two independent radiologists and two experienced oncologists.

Statistical design. The study was designed as a groupsequential clinical trial and an intent-to-treat analysis. An interim analysis based on the O'Brien/Fleming boundary values was performed when $50 \%$ of the end points had been reached. The randomization of patients into two treatment Arms was performed according to the method of random permuted blocks within strata. Stratification factors comprised limited and extensive disease. Dynamic balancing was performed by the hospital. Pearson's $\chi^{2}$ test (or Fisher's exact test, when appropriate) was used for the comparisons of categorical variables. Time-to-event analysis was performed and survival distribution was estimated by the Kaplan-Meier curve and treatment comparison was done using the long-rank test. All reported p-values are two-sided. A p $<0.05$ was considered significant. The primary end-points were median survival, median TTP and tolerance and the secondary end-point was response rate. The accrual time was 54 months and the median time, 36 months.

\section{Results}

From January 2003 till July 2007, 108 patients were enrolled in the study. Four patients underwent one course of treatment $2(5 \%)$ from each Arm, and then, due to brain metastases, 
Table I. Patients' demographics and disease characteristics at baseline.

\begin{tabular}{lccc}
\hline & $\begin{array}{c}\text { Arm A } \\
\mathrm{n}(\%)\end{array}$ & $\begin{array}{c}\text { Arm B } \\
\mathrm{n}(\%)\end{array}$ & $\begin{array}{c}\text { Total } \\
\mathrm{n}\end{array}$ \\
\hline $\begin{array}{l}\text { No. of patients treated } \\
\text { Gender }\end{array}$ & 53 & 55 & 108 \\
Male & & & \\
Female & 45 & 46 & 91 \\
& 8 & 9 & 17
\end{tabular}

Age (years)

Median

Age range (years)

$\begin{array}{ll}\text { Arm A } & 35-80 \\ \text { Arm B } & 50-76\end{array}$

Performance status

(ECOG)

0
1
2

$\begin{array}{ll}15(28.30) & 16(29.09) \\ 27(50.94) & 29(52.73) \\ 11(20.75) & 10(18.18)\end{array}$

Histology: SCLC

Disease stage

$\begin{array}{lll}\text { Limited disease } & 28(52.83) & 27(49.09) \\ \text { Extensive disease } & 25(47.17) & 28(50.90)\end{array}$

Metastatic site

\begin{tabular}{lccc} 
Liver & $11 / 25(44.0)$ & $12 / 28(42.86)$ \\
Adrenal & $1 / 25(4.0)$ & $2 / 28 \quad(7.14)$ \\
Bone & $3 / 25(12.0)$ & $3 / 28(10.71)$ \\
Contralateral lung & $2 / 25(8.0)$ & $2 / 28 \quad(7.14)$ \\
Brain & $5 / 25(20.0)$ & $5 / 28(17.86)$ \\
Multiple sites & $3 / 25(12.0)$ & $4 / 28(14.29)$ \\
\hline
\end{tabular}

underwent brain radiotherapy. One hundred and eight patients received chemotherapy treatment (53 in Arm A and 55 in Arm B). The patients' demographic and disease characteristics at baseline are shown in Table I. The two Arms of the study were well balanced with respect of total number, age, gender and stage of disease (limited or extensive). The median age of each Arm was 63 years (range 35-80 years in Arm A, and 50-76 years in Arm B).

Compliance with treatment. The total number of chemotherapy cycles was 570 (286 for Arm A and 284 for Arm B). The mean number of cycles was 5.2 for Arm A and 5.3 for Arm B. The median interval for each group of patients was 21 days. In 7 patients in Arm A (13.2\%) and in 8 patients in Arm B (14.5\%) the treatment was delayed due to myelotoxicity. No dose reduction was needed in either Arm of patients. Growth factor was given to 2 patients in Arm A and
Table II. Response.

\begin{tabular}{|c|c|c|c|}
\hline & $\begin{array}{c}\text { Arm A } \\
\text { CDDP-paclitaxel } \\
\text { n=53 } \\
n(\%)\end{array}$ & $\begin{array}{c}\text { Arm B } \\
\text { CDDP-VP-16 } \\
\mathrm{n}=55 \\
\mathrm{n}(\%)\end{array}$ & $\mathrm{p}$-value ${ }^{\mathrm{a}}$ \\
\hline $\mathrm{CR}$ & $6(11.3)$ & 7 (12.7) & 0.822 \\
\hline PR & $32(60.4)$ & $32(58.2)$ & 0.816 \\
\hline SD & $10(18.9)$ & $11(20.0)$ & 0.882 \\
\hline PD & $5 \quad(9.4)$ & $5 \quad(9.1)$ & 0.951 \\
\hline $\mathrm{CR}$ and $\mathrm{PR}$ & $38(71.7)$ & 39 (70.9) & 0.928 \\
\hline
\end{tabular}

aThe $\chi^{2}$ test was used for the response rate comparison.

Table III. Survival time (months).

\begin{tabular}{lcccc}
\hline & $\begin{array}{c}\text { Total sample } \\
\mathrm{n}=108\end{array}$ & $\begin{array}{c}\text { Arm A } \\
\mathrm{n}=53\end{array}$ & $\begin{array}{c}\text { Arm B } \\
\mathrm{n}=55\end{array}$ & $\mathrm{p}$-value \\
\hline Median time & 12 & 12 & 13 & 0.354 \\
$95 \%$ CI & $10.9-13.1$ & $11.0-13.0$ & $11.7-12.85$ & \\
\hline
\end{tabular}

The Kaplan-Meier method was used to survival distribution estimation and the log-rank test for comparison of the two Arms.

\begin{tabular}{lcccc}
\hline TTP (months) & $\mathrm{n}$ & Median time & $95 \%$ CI & p-value \\
\hline & & & & 0.060 \\
A & 43 & 8 & $6.84-9.16$ & \\
B & 43 & 6 & $5.00-7.00$ & \\
\hline
\end{tabular}

3 patients in Arm B. The treatment was completed as per protocol in 39 patients $(73.6 \%)$ in Arm A and 42 patients (76.4\%) in Arm B.

Response to treatment. Responses were analyzed on an intent-to-treat basis. Responses were observed in 38 (71.7\%) patients in Arm A (CDDP-PCT), 6 (11.3\%) of whom had complete responses and $32(60.4 \%)$ partial responses $(95 \%$ CI 44.99-76.07). In Arm B (CDDP-VP16), 39 (70.9\%) patients responded: $7(12.7 \%)$ complete responses and 32 (58.2\%) partial responses (95\% CI 42.19-73.59). No statistically significant difference was observed $(\mathrm{p}=0.815)$. The remaining patients had stable disease or disease progression. Table II shows response.

Survival. For Arm A, TTP was 8 months (95\% CI 6.84-9.16) and for Arm B, 6 months (95\% CI 5.00-7.00). The p-value was 0.060 which approaches a statistically significant difference. The median time of survival for Arm A patients was 12 months (95\% CI 11.0-13.0) and for Arm B patients, 13 months (95\% CI 11.7-14.3). No statistically significant difference was observed $(\mathrm{p}=0.354)$. These results are shown in Table III. TTP and survival are shown in Figs. 1 and 2, respectively. 


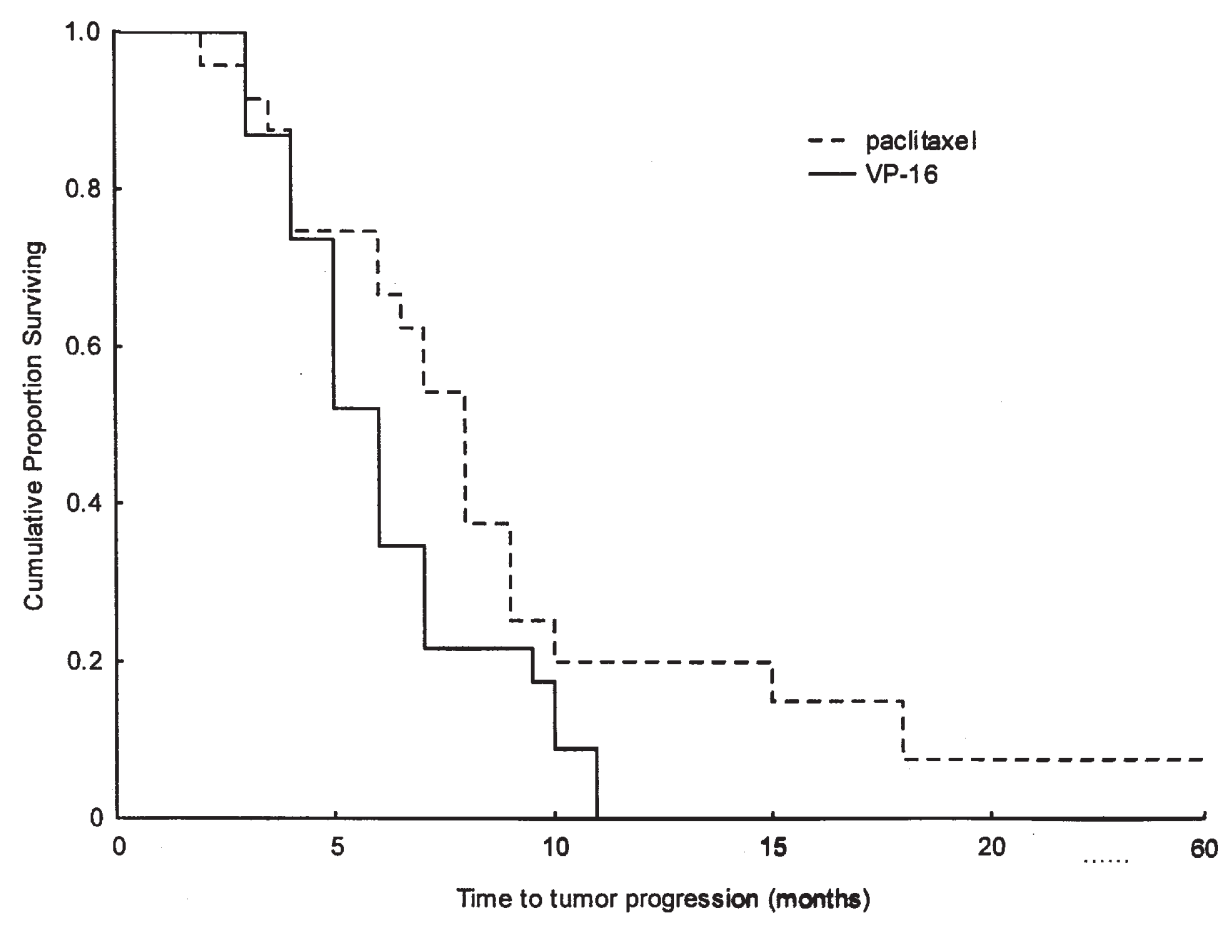

Figure 1. Time to tumor progression (months).

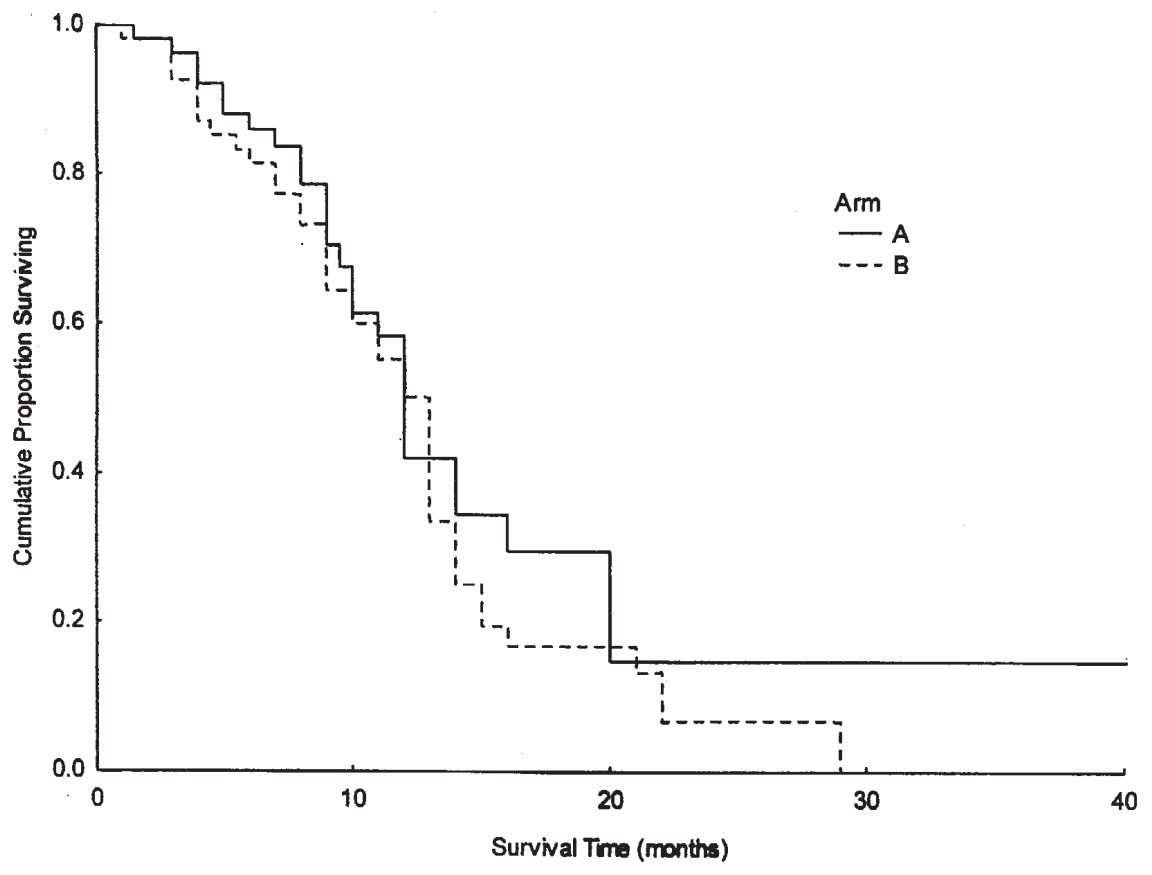

Figure 2. Kaplan-Meier survival time (months).

Toxicity. Adverse reactions were common, but mostly tolerable in patients in both Arms. There were differences in certain toxicities between the two Arms. Serious (grade 3-4) neutropenia was seen in $16.97 \%$ of the patients in Arm A and in Arm B grade 3-4 neutropenia was experienced by $16.36 \%$. Grade 1 and 2 anemia was common at $32.08 \%$ in Arm A and $36.37 \%$ in Arm B. Neuropathy (grade 1-2) was $20.75 \%$ in Arm A and 14.54\% in Arm B. Asthenia was frequent. Nephrotoxicity was higher in Arm B patients, but not very common. No evaluable patient stopped treatment due to toxicity. Adverse reactions are shown in Table IV.

\section{Discussion}

There have been numerous studies trying to improve the results of chemotherapy in small-cell lung cancer. No increase in response and survival was observed when two or three agents in combination were administered (10-14). The 3-drug 
Table IV. Adverse reactions.

\begin{tabular}{|c|c|c|c|c|c|c|c|c|}
\hline & \multicolumn{4}{|c|}{ Arm A (CDDP-PCT) } & \multicolumn{4}{|c|}{ Arm B (CDDP-VP-16) } \\
\hline & \multicolumn{4}{|c|}{ Grade } & \multicolumn{4}{|c|}{ Grade } \\
\hline & $\begin{array}{c}1 \\
\mathrm{n}(\%)\end{array}$ & $\begin{array}{c}2 \\
\mathrm{n}(\%)\end{array}$ & $\begin{array}{c}3 \\
\mathrm{n}(\%)\end{array}$ & $\begin{array}{c}4 \\
\mathrm{n}(\%)\end{array}$ & $\begin{array}{c}1 \\
\mathrm{n}(\%)\end{array}$ & $\begin{array}{c}2 \\
\mathrm{n}(\%)\end{array}$ & $\begin{array}{c}3 \\
\mathrm{n}(\%)\end{array}$ & $\begin{array}{c}4 \\
\mathrm{n}(\%)\end{array}$ \\
\hline Neutropenia & $4 \quad(7.55)$ & $4 \quad(7.55)$ & $7(13.20)$ & $2(3.77)$ & $7(12.73)$ & $9(16.36)$ & $7(12.73)$ & $2(3.63)$ \\
\hline Thrombocytopenia & - & $1 \quad(1.89)$ & $1 \quad(1.89)$ & - & $2(3.63)$ & $2(3.63)$ & - & - \\
\hline Anemia & $10(18.87)$ & $7(13.21)$ & - & - & $12(21.82)$ & $8(14.55)$ & $9(16.36)$ & - \\
\hline Diarrhea & $2(3.77)$ & $2(3.77)$ & - & - & $4 \quad(7.27)$ & $5 \quad(9.09)$ & $2(3.63)$ & - \\
\hline Nausea/vomiting & $4 \quad(7.55)$ & $4 \quad(7.55)$ & - & - & $4 \quad(7.27)$ & $4 \quad(7.27)$ & - & - \\
\hline Mucositis & - & - & - & - & - & - & $1 \quad(1.82)$ & - \\
\hline Neuropathy & $9(16.98)$ & $2(3.77)$ & - & - & $4 \quad(7.27)$ & $4 \quad(7.27)$ & - & - \\
\hline Allergy & - & $1 \quad(1.89)$ & - & - & - & - & - & - \\
\hline Asthenia & $13(24.53)$ & $6(11.32)$ & - & - & $14(25.45)$ & $6(10.91)$ & $1 \quad(1.82)$ & - \\
\hline Nephrotoxicity & $4(7.55)$ & - & - & - & $4 \quad(7.27)$ & $4 \quad(7.27)$ & $1 \quad(1.82)$ & - \\
\hline Alopecia & - & $16(30.19)$ & $10(18.86)$ & - & $2(3.63)$ & $18(32.72)$ & $4 \quad(7.27)$ & - \\
\hline Myalgia & $12(22.64)$ & - & - & - & - & $4 \quad(7.27)$ & - & - \\
\hline Hepatotoxicity & $3(5.66)$ & - & - & - & $1 \quad(1.82)$ & - & - & - \\
\hline
\end{tabular}

combinations simply increased the toxicity (15). It seems that the combination of cisplatin (or carboplatin) and etoposide remains as the standard treatment, and there is no suggested alternative chemotherapy regimen.

PCT has been given before as a second-line treatment or added as a third drug in combination with etoposide and cisplatin: there was an increase in toxicity but not an increase in response or survival $(14,16,17)$. Other Phase I and Phase I-II studies combining paclitaxel with cisplatin and etoposide considered this combination a promising one and the toxicity acceptable (18; Glisson BS et al, Proc ASCO 16: 455, abs. $1635,1997)$.

Another 3-agent study which included cisplatin, etoposide and ifosfamide was effective with a high percentage of complete response. Grade 3-4 myelotoxicity was seen in nearly all of the patients and 5 patients died due to sepsis (19). This indicates that 3-agent chemotherapy may increase the response rate, but the toxicity is an inhibitory factor. Comparing cisplatin-etoposide and carboplatin-etoposide in a randomized Phase III trial showed an equal response rate and survival although toxicity was different in both schedules, but acceptable. Myelotoxicity was higher with carboplatinetoposide whereas nephrotoxicity was higher with cisplatinetoposide (20). The comparison of etoposide-cisplatin with etoposide-cisplatin plus ifosfamide in a randomized study showed a statistically significant difference in TTP and median survival ( $\mathrm{p}=0.039$ and 0.044 , respectively). Three deaths due to toxicity and 17 , to sepsis were reported (21).

Due to myelotoxicity, three-drug treatment appears not to be acceptable in clinical practice. Our trial's intent was to compare two schedules. The experimental combination included cisplatin with paclitaxel. Paclitaxel was elected: a) because it has shown activity, and b) because it has not been extensively tested. The control Arm was given the 'standard' treatment of etoposide and cisplatin. The results were similar with respect to response rate, toxicity and median and overall survival. There was only a tendency towards a statistically significant difference in favor of the CDDP-PCT combination with regard to TTP $(\mathrm{p}=0.06)$. This combination could be used in clinical practice as an alternative to the standard one.

\section{References}

1. Jemal A, Tiwari RC, Murray T, et al: Cancer statistics 2004. CA Cancer J Clin 54: 8-15, 2004.

2. Clark PI, Slevin ML, Joel SP, Osborne RJ, Talbot DI, Johnson PWM, Reznek R, Masud T, Gregory W and Wrigley PFM: A randomized trial of two etoposide schedules in small-cell lung cancer: the influence of pharmacokinetics on efficacy and toxicity. J Clin Oncol 12: 1427-1435, 1994.

3. Moore TD and Korn EL: Phase II trial design considerations for small-cell lung cancer. J Natl Cancer Inst 84: 150-158, 1992.

4. Loehrer PJ, Einhorn LH and Greco FA: Cisplatin plus etoposide in small-cell lung cancer. Semin Oncol 15: 2-8, 1988.

5. Giaccone G, Ferrati P, Donadio M, et al: Reinduction chemotherapy in small-cell lung cancer. Eur J Cancer Clin Oncol 23: 1697-1703, 1987.

6. Jett JR, Everson L, Therneau TM, et al: Treatment of limited stage small-cell lung cancer with cyclophosphamide, doxorubicin, and vincristine with or without etoposide: a randomized trial of the North Central Cancer Treatment Group. J Clin Oncol 8: 33-39, 1990

7. Ettinger DS, Finkelstein DM, Ritch PS, et al: Study of either ifosfamide or teniposide compared to a standard chemotherapy of extensive disease small-cell lung cancer: an Eastern Cooperative Oncology Group randomized study (E1588). Lung Cancer 37: 311-317, 2002.

8. Lowenbraun S, Birch R, Buchanan R, et al: Combination chemotherapy in small cell lung carcinoma: a randomized study of two intensive regimens. Cancer 54: 2344-2350, 1984.

9. Johnson DH, Einhorn LH, Birch R, et al: A randomized comparison of high-dose versus conventional-dose cyclophosphamide, doxorubicin, and vincristine for extensive-stage smallcell lung cancer: a phase III trial of the Southeastern Cancer Study Group. J Clin Oncol 5: 1731-1738, 1987. 
10. Roth BJ, Johnson DH, Einhorn LH, Schacter LP, Cherng NC, Cohen HJ, Crawford J, Randolph JA, Goodlow JL, Broun GO, Ornura GA and Greco AF: Randomized study of cyclophosphamide, doxorubicin, and vincristine versus etoposide and cisplatin versus alternation of these two regimens in extensive small-cell lung cancer: a phase III trial of the Southeastern Cancer Study Group. J Clin Oncol 10: 282-291, 1992.

11. Sundstrom S, Bremnes RM, Kaasa S, Assebo U, Hatlevoll R, Dahle R, Boye N, Wang M, Vigander T, Vilsvik J, Skovlud E, Hannisdal E and Aamdal S for the Norwegian Lung Cancer Study Group: Cisplatin and etoposide regimen is superior to cyclophosphamide, epirubicin and vincristine regimen in smallcell lung cancer. Results from a randomized Phase III trial with 5 years' follow up. J Clin Oncol 20: 4665-4672, 2002.

12. Einhorn LH, Crawford J, Birch R, et al: Cisplatin plus etoposide consolidation following cyclophosphamide, doxorubicin and vincristine in limited small-cell lung cancer. J Clin Oncol 6: 451-456, 1988.

13. Fukuoka M, Furuse K, Saijo N, et al: Randomized trial of cyclophosphamide, doxorubicin and vincristine versus cisplatin and etoposide versus alternation of these regimens in small-cell lung cancer. J Natl Cancer Inst 83: 855-861, 1991.

14. Mavroudis D, Papadakis E, Veslemes V, et al: A multicenter randomized clinical trial comparing paclitaxel-cisplatin-etoposide versus cisplatin-etoposide as first line treatment in patients with small-cell lung cancer. Ann Oncol 12: 463-470, 2001.
15. Therasse P, Arbuck SG, Eisenhower EA, et al: New guidelines to evaluate the response to treatment in solid tumors. J Natl Cancer Inst 92: 205-216, 2000.

16. Ettinger DS, Finkelstein DM, Sarma RP, et al: Phase II study of paclitaxel in patients with extensive disease small cell lung cancer: an Eastern Cooperative Group Study. J Clin Oncol 13: 1430-1435, 1995.

17. Kirschling RJ, Grill JP, Marks RS, et al: Paclitaxel and G-CSF in previously untreated patients with extensive stage small cell lung cancer: a phase II study of the North Central Cancer Treatment Group. Am J Clin Oncol 22: 517-522, 1999.

18. Bunn PA and Kelly K: A phase I study of cisplatin, etoposide, and paclitaxel in small cell lung cancer. Semin Oncol 24 (Suppl. 12): 144-148, 1997.

19. Loehrer PJ, Rynard S, Ansari R, et al: Etoposide, ifosfamide and cisplatin in extensive small-cell lung cancer. Cancer 69: 669-673, 1992.

20. Skarlos DV, Samantas E, Kosmidis P, et al: Randomized comparison of etoposide-cisplatin vs. etoposide-carboplatin and irradiation in small-cell lung cancer. Ann Oncol 5: 601-607, 1994.

21. Loehrer PJ, Ansari R, Gonin R, et al: Cisplatin plus etoposide with or without ifosfamide in extensive small-cell lung cancer: a Hoosier Oncology Group Study. J Clin Oncol 13: 2594-2599, 1995. 